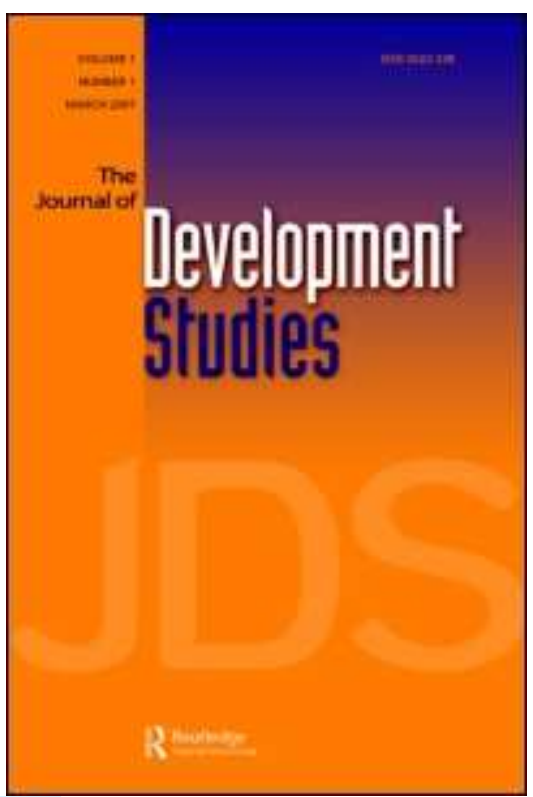

\title{
Modernization and Time Preferences in Tanzania: Evidence from a Large-Scale Elicitation Exercise
}

\begin{tabular}{|r|l|}
\hline Journal: & Journal of Development Studies \\
\hline Manuscript ID: & FJDS-2010-Jan-0042.R3 \\
\hline Manuscript Type: & Original Manuscripts \\
\hline Keywords: & $\begin{array}{l}\text { Tanzania, Urban < Human Geography, Rural < Human Geography, } \\
\text { Time preferences, Modernization }\end{array}$ \\
\hline \multicolumn{2}{|c}{} \\
\hline
\end{tabular}

\section{SCHOLARONE \\ Manuscripts}




\section{Introduction}

People continuously make choices that involve trade-offs between costs and benefits at different points in time. This is the case when decisions are made about investments, trade contracts, credit use (Pender, 1996; Meier and Sprenger, 2007), prevention of infectious diseases (Offe, 2001), and the exploitation of common pool resources (Fehr and Leibbrandt, 2008) among others. When making such decisions people may be influenced by their time preferences. Because of considerable heterogeneity among individuals on this and the importance of individual preferences for explanations of poverty, growth and development (Cardenas and Carpenter, 2008), it is useful for development scholars and policy makers to understand the key socio-economic correlates of individual time preferences.

Within economics literature it is commonly assumed that time preferences are correlated with poverty; with poor people having a preference for the short-term (Fisher, 1930; Lawrance, 1991; Holden et al., 1998). It is also argued that short-term time preferences keep poor people poor by discouraging long-term investments (Becker and Mulligan, 1997; Pennings and Garcia, 2005). Though empirical evidence on the relationship between poverty and time preferences in modern western societies is abundant, evidence for the African continent is scarce. 
In this paper, we present the results of a series of 'choice' experiments which elicited time preferences for more than 1700 individuals in the urban and rural regions of Tanzania's Southern Highlands. We observed significantly higher levels of impatience in urban than in rural areas. Given the commonly assumed positive correlation between poverty and impatience, this result is intriguing as poverty is generally more widespread in rural areas. It suggests that the positive correlation between poverty and impatience is overruled by other characteristics that differ between urban and rural areas. Inspired by anthropological literature on the African concept of time, we test the hypothesis that higher levels of impatience in urban regions are related to higher degrees of 'modernization'. Modern societies generally place a greater emphasis on the efficient use of scarce resources including time. In traditional African societies people place a relatively lower value on time control and availability compared to modern African societies (Mbiti, 1968), which translates into lower impatience levels.

To test this hypothesis we proceed in the following way. First, to disentangle the effect of living in urban (or rural) areas on time preferences from influences related to socio-economic differences between these areas we make use of regression techniques. Also, after controlling for different socio-economic characteristics discount rates in urban areas remain significantly higher than in rural areas. This indicates that differences in time preferences between urban and rural areas are due to 'unobservable' differences (i.e. differences we do not control for). One such difference is modernization. Second, investigating additional determinants of impatience, we observe that, contrary to the existing literature, education levels correlate positively with individual discount rates. Considering education a primary vehicle of modernization to traditional societies in Tanzania, this result supports the hypothesized positive influence of modernization on impatience. By doing so, our study shows that caution is warranted when making policy recommendations based on assumptions about time preference and its correlates that lack cross-cultural validity. The rest of this article is structured as follows. We first review literature from both economics and anthropology that shed light on time preferences and its relation with individual socio-economic characteristics, such as poverty, education and modernization. We then present the research design and empirical results. A final section concludes. 


\section{Literature}

\section{Poverty and Time Preferences}

Economists have extensively studied time preferences (for a recent literature review see Frederick et al., 2002), an interest which goes back to Adam Smith who identified the importance of inter-temporal choice for the wealth of nations. When people decide between economic options at different points in time, it is assumed that they discount the future utilities of each option to the present and then choose the option with the highest discounted utility. The most commonly accepted model that describes such behaviour has been termed the 'discounted utility model.' For more than three decades, discount rates have been empirically measured either through elicitation exercises or through observation of real behaviour. A growing number of studies have looked for the correlates of individual time preferences, such as income and poverty.

This interest, however, is not new in the economics literature. Eighty years ago Fisher stated, 'A small income, other things being equal, tends to produce a high rate of impatience, partly from the thought that provision for the present is necessary both for the present itself and for the future as well, and partly from lack of foresight and self-control' (1930: 72). Numerous empirical studies have confirmed this (Hausman, 1979; Lawrance, 1991; Green et al., 1996; Harrison et al., 2002).

Field studies in developing countries have also found negative correlations between wealth-income and impatience. Kirby et al. (2002) elicited discount rates from the Tsimane in Bolivia and found that they decreased with recent income but not with wealth. Several studies from Southeast Asia reported similar results. Anderson et al. (2004) found large urban/rural differences in Vietnam. People who lived in rural areas had significantly higher discount rates. They attribute these differences to the higher poverty rates in rural areas. Another study on Vietnam (Tanaka et al., 2006) observed a similar pattern when comparing rich and poor villages. In the Philippines, Ashraf et al. (2006), using hypothetical choice questions which queried preferences between amounts to be received today or one month hence, observed a strongly negative influence of household income on impatience. Pender (1996), using a series of binary choice questions which offered a specified quantity of rice at a particular date, or alternative quantities at another, found that wealthier households in India also have lower discount rates. 
On the African continent, empirical evidence on the relation between poverty and time preferences is scarce. Making use of hypothetical choice questions in Zambia, Holden et al. (1998) did not observe any effect of income on impatience, but they did identify a significantly positive effect of liquidity constraints on impatience. In Ethiopia, they found a negative relationship between income and impatience. Also in Ethiopia, Klemick and Yesuf (2008), making use of real financial incentives, found that impatience falls with greater livestock wealth but increases with larger landholdings. These studies suggest that the relation between time preferences and economic indicators, such as wealth, income or liquidity constraints, is less straightforward in Africa than has been documented in studies on other continents. A possible reason for this may be the low weight these studies attach to the cultural dimension.

\section{The Concept of Time in Traditional African Societies}

Traditional African societies are culturally very distinct from the Western societies on which time preference literature has generally focused. Anthropologists and sociologists have shown how peoples' views of time are highly dependent on culture (Munn, 1992) and social organization (Goody, 1991). Differences between modern and traditional African societies regarding conceptions of time have been documented by Mbiti (1968). Two stereotypes are distinguished: the concept of time of traditional African societies and the telos-driven linearity of the modern concept of time. In the modern time concept, time is linear and mechanical with the future arriving at a constant speed. In the traditional African concept of time, time only comes into existence with the arrival of new events. When an event occurs it becomes part of 'Zamani' (i.e. the past in Swahili). There is another element of time called 'Sasa' (i.e. in Swahili, the immediate past, present, and immediate future). This term does not, however, include the very remote future. Generally speaking, it is not common for people in Africa to speculate too much about the future. Surrounded, as they are, by considerable uncertainty, often with low levels of control over their lives, it is very unlikely that the future will be what they expect. ${ }^{1}$ Time control and availability are, therefore, not a matter of great concern.

In modern societies, in contrast, there has been an increasingly more accurate measurement of time (on this evolution, see Barnett, 1998). Accurate time measurement has been a prerequisite of the complex social systems that mark industrial economies (Goody, 1991: 33). For the division of labour, as one of the key drivers of industrialization, to be successful, coordination of time measurement was crucial. Whereas in traditional societies the allocation of time is typically linked to nature which is often unpredictable, with 
industrialization and modernization mechanical time keeping has imposed a predictable pace of time.

What are the implications for discounting? One could hypothesize that the present bias in the traditional concept of time would lead to higher discounting. This would be plausible if there were a fixed amount of time. However, in the traditional concept of time no pre-existing stock of time is assumed to exist. Time scarcity is not an issue (one cannot 'lose time') leading to a complete absence of preferences over time, hence no discounting.

It is important to emphasize that in most parts of Africa, modernization is neither homogeneous nor uniform, so that the two stereotypes of traditional and modern views on time tend to coexist. In most African societies, individual time preferences will therefore be influenced by both views on time, but the weight each of them receives may strongly differ depending on the modernization of the society people belong to, and with the modern view on time being more prevalent in societies with higher levels of modernization. As modernization is driven largely by urbanization and industrialization (Inglehart, 2001), a germane division of time conceptions is between urban and rural areas. We therefore assume that the modern view on time will receive a higher weight in urban than in rural areas, leading to higher discounting.

During our field stay, we could clearly observe how the pace of time in Tanzania varies between urban and rural areas. In comparison with rural areas, public life in urban areas is characterized by a high speed, 'fasta-fasta'. The photocopy shop that helped us with reproducing the questionnaire used for our study was a good example. The owner was always busy and rushing, almost never late, and he has modern photocopy machines that allow him to maximize productivity. He also has individual personal computers with internet access that he rented for a fixed price per time unit. The differences in time preferences between urban and rural areas also correlate with differences in economic activities. Most dominant activities in urban areas are trade and services. These activities are organized according to a fixed and rather strict schedule (shops open and close at a specific moment in time). Economic activity in rural areas, in contrast, is determined by the agricultural cycle and by unpredictable and uncontrollable climate conditions.

\section{Education and Modernization}

An important vehicle that brings modernization may be education. That education may lead to modernization in the Tanzanian context is illustrated by the ethnographic study of Stambach 
(2000). She illustrates the influence of education on modernity and eventually impatience based on a conversation with a stay at home mother

'... who like many of her neighbours, compared and contrasted herself with madada wa mjini - big sisters of the city. ... [who] had attended one or two years of secondary schooling and in some cases had even graduated. Theirs was the world of fast cars and VCRs, of disco dancing and Coca-Cola. To [Mama Stellah], many students in the first graduating class at Mkufi were Big sisters of the city; they were urban-oriented, fashion-conscious, and impatient with the ways of their mothers' (Stambach, 2000: 62).

That education, through its influence on modernization, increases impatience contrasts sharply with economic theory that actually predicts a negative influence of education on impatience. In economics, discounting of future events, transactions, etc. relative to those in the present, is attributed to a limited capacity of people to conceive or imagine the future; which then leads to an underestimation of future wants. According to Pigou (1920), 'our telescopic faculty is defective, and we, therefore, see future pleasures, as it were, on a diminished scale.' This 'telescopic faculty' is assumed to be positively correlated with education. Becker and Mulligan (1997) modelled this within a discounted utility framework, taking account of the effort necessary to imagine future situations. Education then reduces the minimum required effort to form a mental picture of the future, leading to lower impatience levels.

Recent empirical literature confirms these predictions. Harrison et al. (2002) found in Denmark that peoples' degree of impatience declines as their education level increases. Similar results have been found in developing countries. Kirby et al. (2002) found that discount rates of the Tsimane in the tropical rain forests of Bolivia are negatively correlated with education and literacy. Bauer \& Chytilová (2010) found that education significantly reduces the individual discount rates of men in Ugandan villages.

Making the link between education and modernization, Fisher (1930: 81) concludes that more traditional societies pay less attention to future states, because of their low levels of education. That people with lower education pay lower attention to future states is also implied by our 'modernization' hypothesis. An important difference, however, lies in its implications for discounting, hence impatience. Whereas economic theory predicts that a present bias lowers the value people give to future states, which then translates into higher discounting, our hypothesis actually predicts lower discounting. We argue that a present bias 
in the African context is actually the result of a higher weight given to the traditional African concept of time. As explained before, in the traditional African concept of time no preexisting stock of time is assumed ('you can never lose time', Mbiti, 1968), leading to a complete absence of time preferences, hence discounting. Education as a primary conveyer of modernization then induces people to give a higher weight to modern time conceptions, leading to higher discount rates.

\section{Design and Procedures}

The most common approach to empirically elicit time preferences consists of a procedure whereby participants are presented with a list of pair-wise options and asked to select one from each pair (Coller \& Williams, 1999; Harrison et al., 2002). The options in each pair differ in the date of payment. When moving down the list, the amount of one option typically increases while the other remains fixed. At a certain point the participant's preference switches from one option to the other, thus giving an approximation of the indifference point and the related discount rate.

Although this is the most commonly followed approach in experimental economics, we expected poorly educated participants to have difficulties with it as it is rather abstract and requires considerable repetition. The few studies that elicited time preferences through such experiments in Africa identified similar concerns and simplified procedures. Bauer and Chytilova (2010) reduced the number of choices to five and Holden et al. (1998) only asked up to the switching point. Klemick and Yesuf (2008) simplified even more by presenting respondents only one pair of options.

We decided to pursue an alternative approach that we expect to score high on both simplicity and data richness. Our approach consists of a 'titration procedure' with only three consecutive choices. Whereas for the first choice the two options were the same for all participants, the options for the second and third choices were dependent on the previous choices made. ${ }^{2}$ Basically, each participant was asked to choose between receiving 1000 TSH after one month (Option A) or a higher amount after three months (Option B). The options presented in the second (third) choice were dependent on their answer to the first (second) choice. If the participant preferred Option A (or B), for the next choice we increased (or reduced) the amount of Option B, keeping the amount of Option A constant. ${ }^{3}$ Table 1 shows how we changed Option B with each possible sequence of options chosen in the previous choices. 
Table 1. Options used in the time elicitation exercise

\begin{tabular}{cccc}
\hline Choice & $\begin{array}{c}\text { Sequence of prior } \\
\text { options chosen }\end{array}$ & $\begin{array}{c}\text { Option A } \\
\text { (after 1 month) }\end{array}$ & $\begin{array}{c}\text { Option B } \\
\text { (after } 3 \text { months) }\end{array}$ \\
\hline 1 & & $1000 \mathrm{TSH}$ & $1500 \mathrm{TSH}$ \\
\hline 2 & A & $1000 \mathrm{TSH}$ & $1750 \mathrm{TSH}$ \\
3 & B & $1000 \mathrm{TSH}$ & $1250 \mathrm{TSH}$ \\
3 & AA & $1000 \mathrm{TSH}$ & $1900 \mathrm{TSH}$ \\
3 & AB & $1000 \mathrm{TSH}$ & $1600 \mathrm{TSH}$ \\
3 & $\mathrm{BA}$ & $1000 \mathrm{TSH}$ & $1400 \mathrm{TSH}$ \\
\hline
\end{tabular}

TSH = Tanzanian Shilling; 1200 TSH = 1 US\$.

By conditioning the B options to the decisions made in the previous choices, with each choice we fine-tune the intervals of discount rates of each respondent. Each possible sequence of decisions corresponds to one specific interval of discount rates (Table 2). ${ }^{4}$ As a result, with participants making only three decisions we can cover a range of eight possible intervals of discount rates. For instance, one who prefers Option B in the three consecutive choices (category 1), hence prefers to receive $1100 \mathrm{TSH}$ after three months above receiving $1000 \mathrm{TSH}$ after one month has a monthly discount rate lower than $4.45 \%$. This upper bound is calculated as the result of the difference between the A and B Options relative to the B Option, converted into a monthly rate. The latter is done by calculating $\sqrt{(1+r)}-1$. However, one who prefers Option B in the two first choices but in the third choice prefers 1000 TSH after one month above 1100 TSH after three months (category 2), has a monthly discount rate that is higher than $4.45 \%$. We also know that in the second choice receiving $1250 \mathrm{TSH}$ after three months was preferred above 1000 TSH after one month. The upper bound of the monthly discount rate that corresponds to this choice is $9.54 \%$, equal to $(1250-1000) / 1250$, converted into a monthly rate. The other intervals are calculated by following the same procedure.

Note that both options were paid out in the future. The alternative would be to let the respondent choose between an 'instant' option and a future option. This was the procedure followed in the three African studies mentioned before (Bauer and Chytilova, 2010; Klemick and Yesuf, 2008; Holden et al., 1998). This, however, could bias the revealed discount rate if the future option involved additional costs; because of uncertainty about the experimenter's 
Table 2. Intervals of discount rates

\begin{tabular}{ccc}
\hline Category & Sequence of options chosen & Monthly discount rate \\
\hline 1 & BBB & $<4.45 \%$ \\
2 & BBA & $4.45 \%-9.54 \%$ \\
3 & BAB & $9.54 \%-13.39 \%$ \\
4 & BAA & $13.39 \%-15.47 \%$ \\
5 & ABB & $15.47 \%-17.26 \%$ \\
6 & ABA & $17.26 \%-19.52 \%$ \\
7 & AAB & $19.52 \%-21.40 \%$ \\
8 & AAA & $>21.40 \%$ \\
\hline
\end{tabular}

As shown in recent literature, discount rates partially depend on the time frame used, with shorter time frames leading to higher discount rates; which is rationalized by models of hyperbolic discounting (e.g. Klemick \& Yesuf, 2008). It is likely that the modernization hypothesis might be more easily confirmed for shorter (for example, a few days) than for longer time frames, as discounting will be more important for people who give a higher weight to the modern concept of time (alternatively, the time frame effect will be weaker for people who give lower weights to the modern concept of time). Using a two months difference between the two options therefore seems us a reasonable time frame.

Another methodological issue relates to how future (deferred) payments are guaranteed. With experimental studies in the West, this is relatively easy because of a sound banking system. Studies in field labs in developing countries, however, often face organizational and/or systemic problems that affect the credibility of such payments. Consequently, most elicitation studies in developing countries have made use of hypothetical questions, i.e. without real payments (Ashraf et al., 2006; Barr and Packard, 2000). Those studies that did use real payments either used a very small sample (Pender, 1996; Kirby et al., 2002) or only paid a random sub-sample of the participants (Bauer et al., 2008).

Recent exceptions are Klemick and Yesuf (2008) in Ethiopia and Bauer and Chytilová (2009) in India. To guarantee future payments, the first study used a certificate signed by the 
local peasant association redeemable on the date indicated in the experiment. The second study guaranteed future payments with cash certificates signed by the chief of an NGO they cooperated with, a local leader and a social worker familiar to the communities where they organized the elicitation exercises. The social worker was responsible for delivering the amount specified on the cash certificate on the given date. Both studies managed to obtain a sample of around 400-500 individuals.

We set up a similar payment system. We used cash certificates that the participants could redeem in the office of a well-known local microfinance bank at a specific point in time (i.e. after one or three months). The fact that our procedures put less weight on the research team ${ }^{5}$ (instead of relying on a social worker, participants themselves had to come and cash their payments) allowed us to obtain a much larger sample (i.e. more than 1700 respondents). We are aware, however, that the selection of a microfinance bank in the urban centre for redeeming participant payment certificates may lead to differences in incentives between urban and rural participants due to travel costs. To minimize these differences people did not have to come personally to the bank and cash the certificates. ${ }^{6}$ Details of the parameters and procedures involved are found in the Web appendix.

The elicitation exercise was embedded in a large socio-economic household survey in the Southern Highlands of Tanzania. In total, 1758 individuals participated: 406 in the urban centre and 1353 in 11 surrounding rural villages. Whereas the rural respondents were randomly selected from the total population of selected rural villages, the urban respondents were randomly selected from current and former clients of a local microfinance bank. We did so as there was no available census of residents in the area.

\section{Results}

In this section, we present the empirical results of our study. We first compare discount rates between urban and rural samples. In the next step, we use regression techniques to eliminate possible biases due to socio-economic differences between urban and rural areas that might correlate with individual discount rates. Thereafter, we estimate regressions for the urban and rural samples separately in an attempt to find additional determinants of impatience and provide further evidence for the modernization hypothesis. 
Figure 1. Distribution of discount rates by area and sex
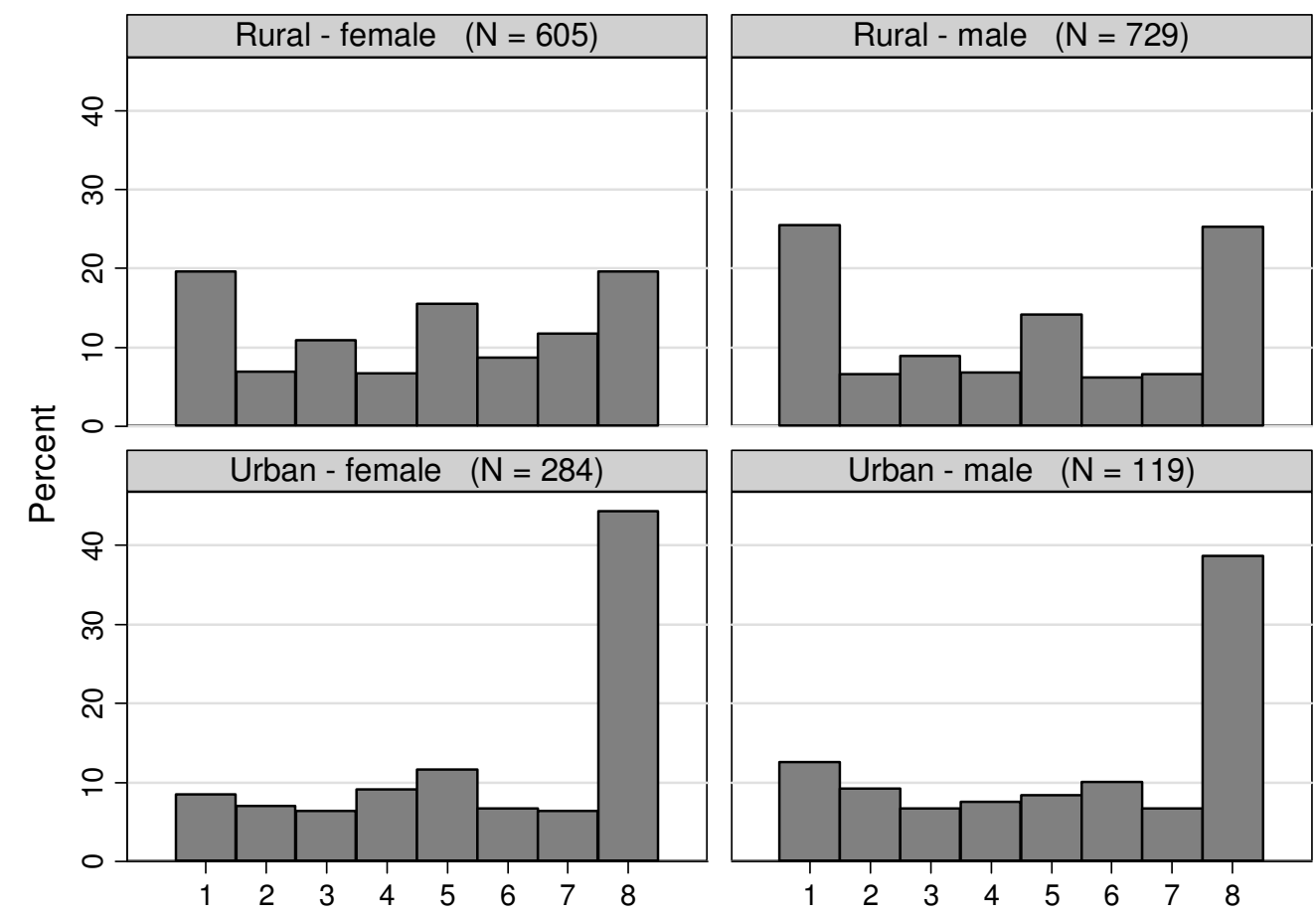

\section{Rural-Urban Differences in Time Preferences}

Figure 1 shows the distribution of time preferences for urban and rural samples, for men and women separately. We observe that around $10 \%$ of urban participants and $20 \%$ of rural participants preferred Option B in all three choices (category 1). Some of them may have done so because of having relatively low discount rates. Others may not have applied any discounting at all and preferred Option $\mathrm{B}$ in all choices simply because it has the largest payoff. As the group of participants that fall under category 1 is limited in size, we can conclude that most of the participants followed a discounting logic when comparing Options $\mathrm{A}$ and $\mathrm{B}$.

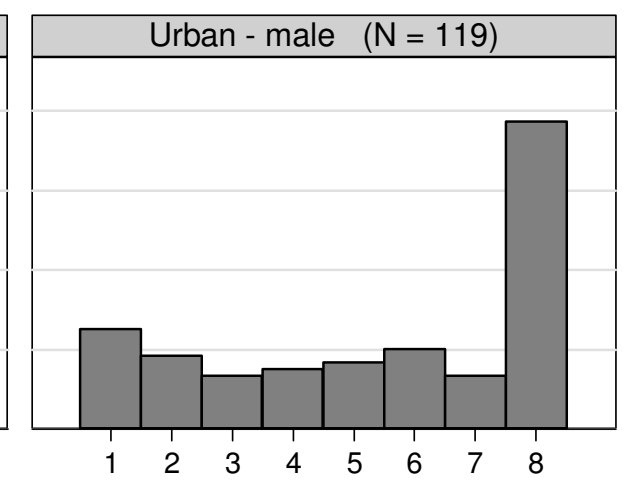

Figure 1 also shows that more than $20 \%$ of the rural participants and more than $40 \%$ of the urban participants preferred Option A in the three consecutive choices (category 8) which corresponds to a monthly discount rate of more than $21.40 \%$. Differences in time preferences between men and women are negligible. According to a Mann-Whitney test, differences are statistically insignificant in the urban area $(Z=-1.248$; two-sided $P=.212)$ and the rural area ( $\mathrm{Z}=-0.844$; two-sided $\mathrm{P}=.398$ ). This is consistent with the findings of Kirby et al. (2002) and Anderson et al. (2004), who found no differences between men and women in Bolivia and 
Vietnam, respectively. Time preferences, however, do differ substantially between urban and rural areas, with discount rates being substantially higher in the urban centre than in surrounding rural villages. To test whether this difference is statistically different from zero, we pool men and women (as differences between men and women in urban and rural areas are insignificant) and apply a Mann-Whitney test. We find that this difference is statistically significant $(\mathrm{Z}=-7.613$; two-sided $\mathrm{P}=.000)$.

Remember, however, that in the urban areas only individuals were selected who are or had been clients of a particular local microfinance bank. When this program targets individuals with specific characteristics possibly related to time preferences, there may be a selection bias and the urban and rural samples may be incomparable. Since for the urban area we only selected (ex) clients, education and wealth may be higher in the urban sample compared to the total urban population (under the assumption that people with access to microfinance services are, on average, less poor and have more education (Navajas et al., 2000). However, to the extent that wealth and education reduce impatience, this would only lead to an underestimation of observed differences between urban and rural samples. To reduce any such bias, we compare the urban sample only with those individuals in the rural sample that have access to microfinance services. According to a Mann-Whitney test, the difference in time preferences remains statistically significant $(Z=-4.492$; two-sided $P=$ $.000)$.

To disburse the money of the time preference elicitation exercise, we relied on the same microfinance bank that was used to sample urban respondents. We are aware that this could bias rural-urban differences. For instance, that urban participants have better access to the institution's services, may lead to lower reported impatience levels if they are more confident that they will really get the money. As this would underestimate impatience differences between rural and urban samples (and thus lead to conservative estimates), we expect differences to hold without any such bias. To test this, we compare the rural participant sample with only the ex-clients in the urban sample. Applying a Mann-Whitney test, we observe that differences in discount rates between urban and rural samples remain statistically significant $(\mathrm{Z}=-5.163 \text {; two-sided } \mathrm{P}=.000)^{7}$

\section{Controlling for Biases between Urban and Rural Samples}

The observed differences in time preferences between urban and rural samples may also be influenced by differences in key socio-economic variables that have been identified as important determinants of time preferences in the empirical literature (e.g. poverty, education, 
age). It is important to disentangle the effect of living in urban (or rural) areas on time preferences from influences related to socio-economic differences between these areas. So far, we only looked at a few possible biases, and only looked at one possible bias at a time. To tackle these biases we will estimate a series of regression models that control for these socioeconomic differences. If after adding these controls there remain differences between urban and rural samples on time preferences, these are likely due to 'unobserved' differences between urban and rural areas (i.e. differences we did not control for), such as modernization.

In particular, we estimate a regression model with the discount rate as dependent variable. As the dependent variable is not continuous but consists of several ranges, OLS regression would lead to inconsistent estimates, meaning that the coefficients will not necessarily approach the "true" population parameters as the sample size increases. An interval regression' specification is more appropriate as it deals econometrically with all types of censoring (left censoring, interval and right censoring) and by doing so guarantees that we get unbiased estimates. The large proportion of urban participants that are in the highest interval that is right-censored (Figure 1) would therefore not pose a problem for the estimated coefficients of socio-economic correlates. The interval regression has the following specification:

$$
y_{i}^{*}=\beta_{0}+U_{i} \cdot \beta_{1}+\varepsilon_{i}
$$

$y_{i}^{*}$ is the latent dependent variable that measures the monthly discount rate. This variable is never observed; only the interval where it falls into. In other words, we assume a function $y_{i}=t\left(y_{i}^{*}\right)$ that links this latent variable to an observed category of discount factor $y_{i}$

$$
t\left(y_{i}^{*}\right)= \begin{cases}1 & \text { if } \\ 2 & \text { if } c_{1}<y_{i}^{*} \leq c_{1} \\ 3 & \text { if } c_{2}<y_{i} \leq c_{2} \\ 4 & \text { if } c_{3}<y_{i} \leq c_{4} \\ 5 & \text { if } c_{4}<y_{i}^{*} \leq c_{5} \\ 6 & \text { if } c_{5}<y_{i}^{*} \leq c_{6} \\ 7 & \text { if } c_{6}<y_{i}^{*} \leq c_{7} \\ 8 & \text { if } c_{7}<y_{i}\end{cases}
$$

$\mathrm{U}_{\mathrm{i}}$ is a rural-urban dummy, the use of which allows us to estimate the influence of living in a rural/urban area on individual discount rates. However, the estimated coefficient of the rural-urban dummy will be biased if we omit covariates that correlate with time preferences 
and are not evenly distributed in the rural and urban samples. There are different ways to tackle this problem. One way is to add these covariates as additional variables in the regression. Another approach is the use of propensity scores. Propensity scores are the conditional probabilities (propensities) of being in the treated group given a set of covariates. In our analysis we consider the urban sample as the treated group. The use of propensity scores allows us to balance the observations in such a way that assignment to the urban or rural samples is independent of the covariates conditional on the propensity score. There are different methods to use the propensity score to adjust the regression. One method is to simply add the propensity score as covariate (Rosenbaum and Rubin, 1983); another is to reweight observations with the inverse of the propensity score (Imbens, 2000; Hirano and Imbens, 2001). We will make use of these different methods and compare the results as a robustness test. ${ }^{8}$

Table 3. Descriptive statistics of rural and urban samples

\begin{tabular}{lccc}
\hline & Urban & Rural & $\mathrm{P}^{\mathrm{a}}$ \\
\hline Age & 33.64 & 43.06 & .000 \\
Education (years) & 7.40 & 4.76 & .000 \\
Number of children & 2.22 & 2.64 & .000 \\
Lack of food shortages (dummy) & $55.3 \%$ & $41.4 \%$ & .000 \\
\hline Sex (1 = male; 0 = female) & $29.4 \%$ & $54.6 \%$ & .000 \\
Never migrated (dummy) & $42.2 \%$ & $74.3 \%$ & .000 \\
Household size & 4.97 & 5.47 & .000 \\
\hline Self-employment (crop farming) & $47.16 \%$ & $99.93 \%$ & .000 \\
Self-employment (livestock raising) & $37.04 \%$ & $70.69 \%$ & .000 \\
Self-employment (non-farming) & $73.83 \%$ & $22.07 \%$ & .000 \\
Paid employment & $10.40 \%$ & $3.33 \%$ & .000 \\
Daily labourer & $2.97 \%$ & $19.54 \%$ & .000 \\
\hline & $\mathrm{N}=405$ & $\mathrm{~N}=1349$ & \\
\hline
\end{tabular}

${ }^{a}$ Two-sided $\mathrm{P}$ values of a t-test for comparisons of means in the case of continuous variables, or chi-square for comparisons of dichotomous variables.

To identify covariates that are not evenly distributed in the rural and urban sample while at the same time possibly correlate with time preferences, we look more closely at the socioeconomic differences between the urban and rural samples (Table 3). We observe that respondents in rural areas are older, less-well educated and have more children than those in the urban centre. In the urban sample relatively fewer people faced food insecurity in the last 
two years, which is used as a proxy for poverty. This is consistent with their generally lower poverty levels relative to rural areas. We also observe that in the urban sample we interviewed relatively fewer men than in the rural sample. This is due to the higher proportion of female clients in the microfinance program. Furthermore, we observe that the proportion of people who have never migrated (and thus have lived their entire life in their village) is significantly higher in the rural sample than in the urban sample. The average household size is also larger in the rural than in the urban sample.

Comparing the economic activities between the two samples, we find that selfemployment in crop farming and livestock raising is relatively more important in rural areas whereas self-employment in non-farming activities (i.e. all types of services and commerce) is relatively more important in the urban sample. We also find that the proportion of people that obtain an income as a daily labourer is higher in rural areas, while paid employment (i.e. with a fixed salary from local companies, governments and NGOs) is more important in urban areas.

According to existing literature, of all these socio-economic variables that differ between the rural and urban samples the following are possibly correlated with time preferences: age (Green et al., 1996); education (Bauer \& Chytilová, 2010); number of children (Bauer and Chytilová, 2009) and wealth/poverty (Hausman, 1979; Lawrance, 1991; Green et al., 1996; Pender, 1996; Harrison et al., 2002). These variables will be used to adjust the basic regression specified in equation 1.

While we expect these variables to correlate with time preferences and to differ significantly between rural and urban samples, we also consider variables on which both samples differ but that based on existing literature are not directly expected to correlate with time preferences. We will use these variables for the regressions adjustments as they may be correlated with important unobservable characteristics that do influence time preferences. One such variable is sex. Although the literature is silent about the influence of gender on time preferences, women may have certain characteristics that may make them more or less impatient. For the same reason, we control for the number of household members and we add a dummy equal to one when the subject has never migrated before. By adding the latter dummy variable we are able to control for unobservable characteristics that promote a tendency to migrate and at the same time influence time preferences.

Furthermore, urban-rural differences in the decisions made in the elicitation exercise may be influenced by enumerator characteristics. Remember that the instructions were given by different persons so that we cannot exclude the possibility of enumerator differences in 
demeanour or attitude influencing respondents' choices. To reduce such possible bias we add enumerator fixed effects.

Finally, there may be additional selection biases because of the way how we implemented the elicitation exercise. First, as the urban respondents were randomly selected from current and former clients of a local microfinance bank whereas the rural respondents were randomly selected from the total population of selected rural villages, there may be a bias in access to finance, which possibly correlates with time preferences. Second, as the rewards of the elicitation exercise were only redeemable at the local urban microfinance bank there may be a non-random bias across rural and urban samples related to effort with the elicitation exercise. To test and reduce any such biases we will add further control variables.

Our strategy to estimate the determinants of time preferences and to deal with these biases is the following. In Model 1 we estimate the basic model without any controls, i.e. equation (1). In Model 2 we include all the confounding factors of time preferences discussed above. In Model 3, we replace the rural-urban dummy with two dummy variables equal to one if the respondent lives in a rural area and visited the urban centre at least once last month, and lives in a rural area but did not visit the urban centre in the last month, respectively. We do so to test whether there is a possible effort-related effect on the elicitation of time preferences. If people in the urban centre would have to put less effort to cash their earnings (as the institution that is used to cash receipts is located in the urban centre) and this would bias the elicitation of their time preferences, we would also observe such an effect between rural people who regularly visit the urban centre and those who do not. In Model 4 we also control for access to finance, with a dummy variable equal to one if the respondent has had access to microfinance. We do so to reduce a potential bias introduced by sampling the urban respondents from clients of a local microfinance bank and the rural respondents from the total population of selected rural villages.

Models 5 and 6 use the propensity scores to adjust the regressions. For the calculation of the propensity scores we estimate the likelihood of belonging to the urban sample with a standard probit regression controlling for the above socio-economic characteristics. Table 1 in the Web appendix shows the results. We observe that all coefficients are statistically significant. Figure 1 in the Web appendix shows histograms of the propensity scores in the urban and rural samples. Whereas in Model 5 we will use the propensity score as additional covariate, Model 6 uses the propensity score to reweight the observations in the urban and rural samples. 
Table 4. Determinants of individual discount rates

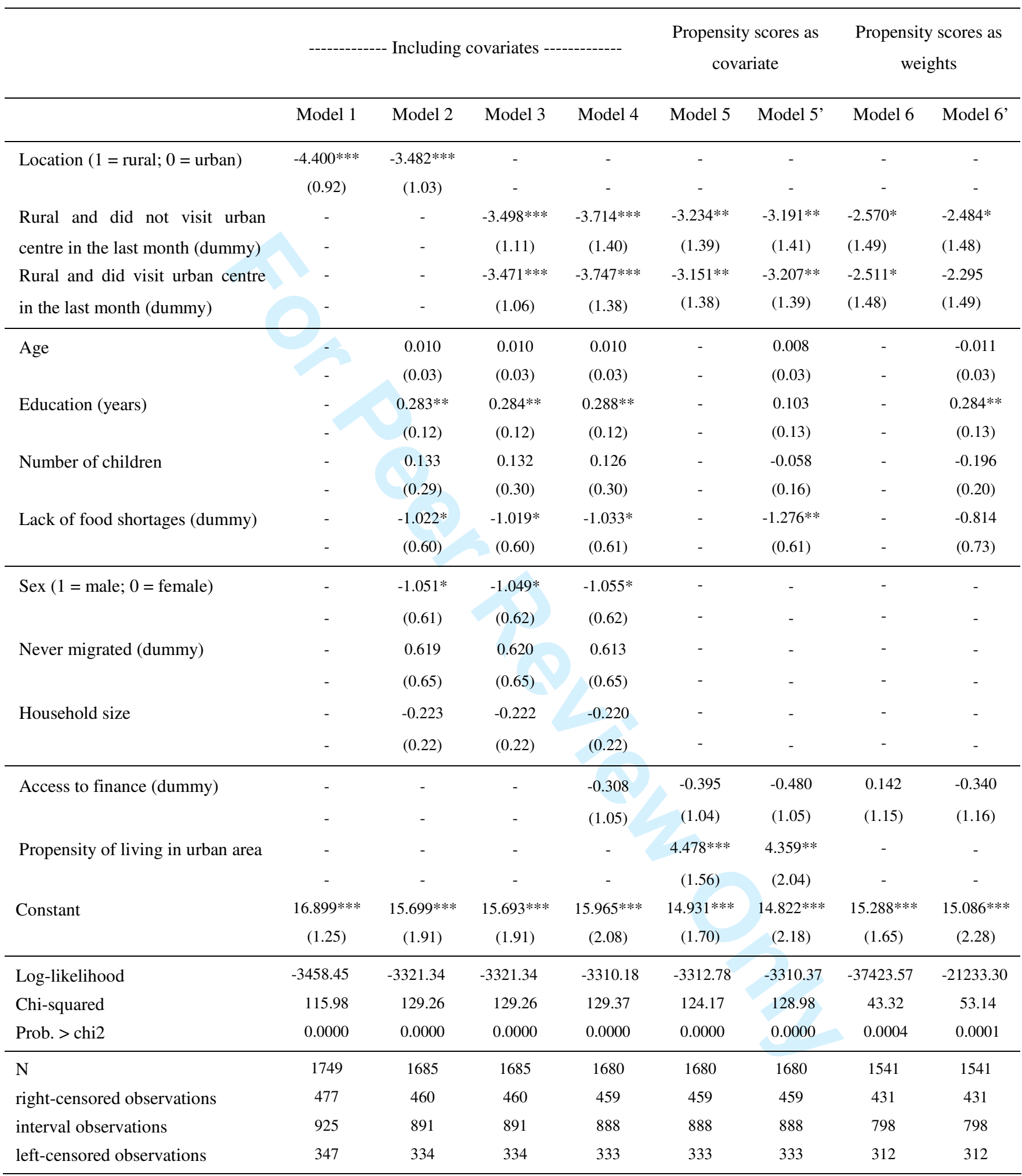

$* \mathrm{p}<0.10,{ }^{* *} \mathrm{p}<0.05,{ }^{* * *} \mathrm{p}<0.01$; Standard errors between brackets; Model 6 and 6': observations have been reweighted by the propensity score (observations with weight $>20$ were excluded). All models have enumerator fixed effects. 
Table 4 presents the results. In Model 1 we observe that people who live in the rural area have a monthly discount rate that is on average $4.40 \%$ lower than people in the urban area. In Model 2 that controls for possible confounding factors of time preferences this effect reduces to $3.48 \%$, but remains highly significant. Model 3 shows that there are no differences between rural people who visited the urban centre at least once in the last month and rural people who did not visit the urban centre in the last month (chi2 $=0.00 ; \mathrm{P}=0.969$ ). This suggests that possible differences in effort to cash the receipts of the elicitation exercise do not bias the elicited time preferences. In Model 4 an additional control for access to finance is added by using a dummy equal to one if one has had access to finance. The coefficients of the two rural dummy variables remain robust to adding this control variable. ${ }^{9}$

In Models 5 and 6 we make use of propensity scores to balance the observations in the two samples. In Model 5 the propensity scores are added as a covariate. We observe that this weakens the effect of living in a rural area, but that the coefficients of the rural-urban dummy variables remain statistically significant at the 5\%. The advantage of using propensity scores in this way is that one can add a subset of the covariates used to estimate the propensity score, to test the influence of these covariates on time preferences. This is done in Model 5', where we add some of the variables that according to the literature possibly correlate with time preferences. Our results confirm existing evidence on the positive relation between poverty and impatience. People who have never had any food difficulties have on average a $1.28 \%$ lower monthly discount rate.

The propensity scores can also be used to reweight the observations in the samples (Imbens, 2000; Hirano and Imbens, 2001). In Model 6 each observation in the urban sample is reweighted by the inverse of the propensity score and each observation in the rural sample by the inverse of one minus the propensity score. As observations with very low propensity scores will get very high weights and therefore the results may become sensitive to the inclusion of these observations, we exclude the observations that have a weight larger than 20 . We observe that the effect of living in a rural area is somewhat weaker in this model, while the coefficients of the rural-urban dummy variables remain statistically significant at the $10 \%$.

Assuming that education is a primary vehicle of modernization to traditional societies in Tanzania it is also relevant to look at the coefficient of the education variable. One might expect, however, that the coefficient of education suffers from omitted variable bias, due to its correlation with the types of economic activities the respondents are involved in. Economic activities may exert an important influence on one's daily schedule and therefore also 


\section{Conclusion and Discussion}

Individual time preferences may be important determinants of individual decision making that involve trade-offs between costs and benefits at different points in time. Because of considerable individual heterogeneity in time preferences and the importance of these preferences for explanations of poverty, growth and development, it is useful for development scholars and policy makers to understand the key socio-economic correlates of time preferences.

Many studies have elicited time preferences in industrialized countries with a growing number in developing countries. Yet, only a few of them have been conducted in Sub-Saharan Africa. In this paper, we elicited the time preferences of more than 1700 individuals in the Southern Highlands of Tanzania. Comparing individual time preferences between urban and rural areas, we observed considerably higher impatience in urban areas. This is intriguing given the commonly assumed positive correlation between poverty and impatience (and with poverty being generally more widespread in rural areas). Differences remain significant, after adding further controls, necessary to eliminate possible omitted variable bias. As it is impossible to influence where people live (and therefore this variable is impossible to randomize) any studies on rural-urban differences are particularly vulnerable to such bias. It is therefore important to control for any differences between urban and rural samples on socioeconomic characteristics that may influence time preferences and are not equally distributed between urban and rural samples. Making use of different specifications (using propensity scores and additional covariates) we observe that the difference between rural and urban areas remains robust. 
Making use of the anthropological literature on the African concept of time, we attribute this higher impatience in urban areas to higher degrees of 'modernization.' This is corroborated by the observed positive correlation between impatience and education; with education being a primary conveyer of modernization. Our results may have important consequences for the policy recommendations made in the existing literature.

First, it is generally assumed that higher discount rates lower the valuation of future benefits, hence lower the utility of any decision that defers benefits to the future, as is the case with environmental conservation (e.g. Holden et al., 1998), the use of savings products (Ashraf et al., 2006) and the repayment of credit loans (Meier and Sprenger, 2007). Under this assumption, the many studies that found a positive correlation between poverty and discount rates tend to conclude that poverty stimulates behaviour that is detrimental to society. Our study, in contrast, found that people in urban areas, where poverty levels are generally lower, have actually higher discount rates. Identifying modernization in African societies as a much stronger correlate of impatience than poverty, our results indicate that the existing evidence on the relationship between poverty and impatience should be put into a broader perspective.

Second, most evidence in the literature supports a negative correlation between education and impatience. This is attributed to a positive effect of schooling on children's appreciation of future utility, which lowers their discounting, hence increases their patience. Based on this result policymakers are recommended to invest in education as it reduces children's impatience levels. In our study, in contrast, we find a positive correlation between education and impatience, which we attribute to the close link between education and modernization in African societies, with modernization leading to higher impatience levels.

The underlying assumption we have followed so far is that higher discount rates are less optimal as they make people less willing to undertake long-term investments. Two further observations on this are required, however. First, we should be aware that the optimal discount rate might be different for different livelihoods. Discount rates are only one of the important parameters in any exercise of utility or welfare maximization, as are (time) constraints, preferences and time frames. For example, the fact that commercial activities have a lower turnaround than agricultural activities makes short (long) run time discount rates more (less) relevant for vendors than for farmers. Second, people tend to have higher discount rates in short run than in long run time frames. Such time inconsistencies explain why people often make choices in the short run that are detrimental to their long run interest. This has been increasingly documented in the literature and may be very relevant for policy (Frederick et al., 2002; Klemick and Yesuf, 2008). 


\section{References}

Anderson, C.L., Dietz, M., Gordon, A. and Klawitter, M. (2004) Discount rates in Vietnam. Economic Development and Cultural Change, 52(4), pp. 873-887.

Ashraf, N., Karlan, D. and Yin, W. (2006) Tying Odysseus to the mast: Evidence from a commitment savings product in the Philippines. Quarterly Journal of Economics, 121(2), pp. 635-672.

Barham, B.L., Boucher, S., and Carter, M.R. (1996) Credit constraints, credit unions, and small-scale producers in Guatemala. World Development, 24(5), pp. 793-806.

Barnett, J.E. (1998) Time's Pendulum (New York: Plenum trade).

Barr, A. and Packard, T. (2000) Revealed and concealed preferences in the Chilean pension system: an experimental investigation. Discussion Paper Series, Department of Economics, University of Oxford.

Bauer, M., Chytilova, J., Morduch, J. (2008) Behavioral Foundations of Microcredit: Experimental and Survey Evidence From Rural India, IES working paper 28/2008

Bauer, M. and Chytilová, J. (2009) Women, children and patience: Experimental evidence from Indian villages, IZA DP No. 4241

Bauer, M. and Chytilová, J. (2010) The impact of education on subjective discount rates in Ugandan villages. Economic Development and Cultural Change, 58(4), pp. 643-669.

Becker, G.S. and Mulligan, C.B. (1997) The endogenous determination of time preference. Quarterly Journal of Economics, 112(3), pp. 729-758.

Binswanger, H.P. (1980) Attitudes toward risk: Experimental measurement in rural India. American Journal of Agricultural Economics, 62(3), pp. 395-407.

Blackden, C.M. and Wodon, Q. (eds) (2006) Gender, Time Use, and Poverty in Sub-Saharan Africa, World Bank Working Paper Series, 152 pp. 
Cardenas, J.C. and Carpenter, J. (2008) Behavioural development economics: Lessons from field labs in the developing world, Journal of Development Studies, 44(3), pp. 311- 338.

Coller, M. and Williams, M. (1999) Eliciting individual discount rates. Experimental Economics, 2(2), pp. 107-127.

D'Agostino R.B. (1998) Propensity score methods for bias reduction in the comparison of a treatment to a non-randomized control group. Statistics in Medicine, 17(19), pp. 22652281.

Fehr, E. and Leibbrandt, A. (2008) Cooperativeness and impatience in the tragedy of the commons, IZA DP No. 3625.

Fisher, I. (1930) The Theory of Interest (New York: Macmillan).

Frederick, S., Loewenstein, G. and O'Donoghue, T. (2002) Time discounting and time preference: A critical review, Journal of Economic Literature, 40(2), pp. 351-401.

Goody, J. (1991) Time: Social Organization [1968], in: D.L.Sills (ed.) International Encyclopedia of Social Sciences 16 (New York: Macmillan), pp. 30-42

Green, L., Myerson, J., Lichtman, D., Rosen, S. and Fry, A. (1996) Temporal discounting in choice between delayed rewards: the role of age and income. Psychology and Aging, 11(1), pp. 79-84.

Harrison, G.W., Lau, M.I. and Williams, M.B. (2002) Estimating individual discount rates in Denmark: a field experiment, American Economic Review, 92(5), pp. 1606-1617.

Hausman, J. (1979) Individual discount rates and the purchase and utilization of energy using durables. Bell Journal of Economics, 10(1), pp. 33-55.

Henrich, J. and McElreath, R. (2002) Are peasants risk averse decision-makers. Current Anthropology, 43(1), pp. 172-181.

Hirano, K. \& G.W. Imbens (2001) Estimation of Causal Effects using Propensity Score Weighting: An Application to Data on Right Heart Catheterization, Health Services \& Outcomes Research Methodology, 2, pp. 259-278.

Holden, S.T., B. Shiferaw and Wik, M. (1998) Poverty, market imperfections and time preferences: of relevance for environmental policy? Environment and Development Economics, 3(1), pp. 105-130. 
Imbens (2000) The Role of the Propensity Score in Estimating Dose-Response Functions, Biometrika, 87(3), pp. 706-710.

Inglehart, R. (2001) Sociological theories of modernization, in: N.J. Smelser and P.B. Baltes (eds) International Encyclopedia of the Social and Behavioural Sciences (Oxford: Pergamon), pp. 9965-9971.

Kirby, K., Godoy, R., Reyes-Garcia, V., Byron, E., Apaza, L., Leonard, W., Perez, E., Vadez, V. and Wilkie, D. (2002) Correlates of delay-discount rates: evidence from Tsimane amerindians of the Bolivian rain forest, Journal of Economic Psychology, 23(3), pp. 291316.

Klemick, H. and Yesuf, M. (2008) Do discount rates change over time? Experimental evidence from Ethiopia. Environment for Development Discussion Paper Series DP 0806.

Lawrance, E. (1991) Poverty and the rate of time preference: evidence from panel data. Journal of Political Economy, 99(1), pp. 54-77.

Mbiti, J.S. (1968) African concept of time. Africa Theological Journal, 2, pp. 8 - 20.

Meier, S. and Sprenger, C. (2007) Impatience and credit behaviour: Evidence from a field experiment, FRB of Boston Working Paper No.07-3.

Munn, N.D. (1992) The cultural anthropology of time: a critical essay, Annual Review of Anthropology, 21, pp. 93-123.

Navajas, S., Schreiner, M., Meyer, R.L., Gonzalez-vega, C. and Rodriguez-Meza, J. (2000) Microcredit and the poorest of the poor: Theory and evidence from Bolivia. World Development, 28(2), 333-346.

Offe, J.A. (2001) Smart guys plan for the future! Cultural concepts of time and the prevention of AIDS in Africa. Africa Spectrum, 36(1), pp. 53-72.

Pender, J.L. (1996) Discount rates and credit markets: theory and evidence from rural India. Journal of Development Economics, 50(2), pp. 257-296.

Pennings, J. and Garcia, Ph. (2005) The poverty challenge: How individual decision-making behaviour influences poverty. Economics Letters, 88(1), pp.115-119.

Pigou, A.C. (1920) The Economics of Welfare. London: Macmillan. 


\section{Notes}

1 In Tanzania, wishes regarding the remote future are often combined with 'Mungu akipenda' (i.e. 'if Allah or God wishes'). Also, when saying goodbye, people add the phrase 'Mungu akipenda'.

2 We borrow this titration procedure from Henrich \& McElreath (2002) who implemented it to elicit risk aversion levels among two groups of small-scale farmers: the Sangu in Tanzania and the Mapuche in Chile.

3 Before proceeding to the next choice we removed both cards (from the table). We then presented the reference card (Option A) and the new Option B and asked them to make a new choice. We did so in an attempt to minimize possible autocorrelation between the three consecutive choices as a result of the participants reacting, 'I already told you, I want this card!' if they had previously chosen Option A.

4 Such titration procedure also eliminates the problem of 'multiple switching,' commonly observed with the standard method that consists of presenting a list of 'independent' pairs of options. Although the issue of inconsistent preferences revealed by multiple switching may be interesting, as such (see e.g. Bauer et al, 2008), it is not the focus of our research.

$5 \quad$ Klemick and Yesuf (2008) did not provide any details about whether and how participants were supported to redeem their payments.

6 According to anecdotal evidence, several weeks after our experiment in one of the most remote rural villages a local trader accepted the payment certificates as temporal currency. To account for possible transaction costs to cash the certificates in the urban centre he charged a cost on each received certificate. This suggests that even in very remote areas our payment system produced very credible incentives.

7 Differences also remain significant when comparing ex-clients to rural participants who have access to microfinance services $(\mathrm{Z}=-4.492$; two-sided $\mathrm{P}=.000)$.

8 Propensity scores are commonly used in impact evaluation studies, often combined with matching techniques or stratification to simulate random allocation to treatment and control group in observational studies. The combination with regression analysis is somewhat less common, but more interesting for scholars in development studies who are more familiar with regression techniques than with propensity scores matching or stratification. 
9 We also estimate the same models with an alternative dummy equal to one if they currently have access to finance. The difference lies in the urban sample, where we distinguish current and ex-clients. All presented results are robust to using this alternative control variable. 


\section{Web-appendix A: Time Preference Elicitation Instructions}

"We will ask you some questions that will allow you to earn real money. We will ask you to make a choice between getting money after one month (i.e. in the month of September) and getting money after three months (i.e. in the month of November).

We will give you a paper on which we promise to pay you the amount you have chosen and we will specify the month when this amount can be withdrawn from our account at bank X (name withheld) in Mafinga. We will leave the original of this paper with you and give a copy of it to the bank. Upon presenting this original, the bank official will immediately pay you the amount written on the paper.

Note that you are not required to withdraw the money personally, you can also send a relative, friend, etc. with your original copy. In that case it is sufficient that this person shows the original paper and mentions your name.

You will have to make three choices.

The first choice you have to make is the following. You have to choose between getting $1000 \mathrm{TSH}$, which we will pay you after one month (i.e. in the month of September), or getting the total sum of $1500 \mathrm{TSH}$, which we will pay you after three months (i.e. in the month of November). What do you choose, 1000 TSH after one month or 1500 TSH after three months?

The second choice you have to make is similar. This time, you have to choose between getting the total sum of $1000 \mathrm{TSH}$, which we will pay you after one month (i.e. in the month of September), or getting the total sum of [fill in amount] TSH, which we will pay you after three months (i.e. in the month of November). So, what do you choose, 1000 shillings after one month or [fill in the amount] TSH after three months?

The final choice you have to make is again similar. This time, you have to choose between getting the total sum of $1000 \mathrm{TSH}$, which we will pay you after one month (i.e. in the month of September), or getting the total sum of [fill in amount] TSH, which we will pay you after three months (i.e. in the month of November). So, once again, what do you choose, 1000 TSH after one month or [fill in the amount] TSH after three months?" 
1

2

3

4

After the exercise the cheque was written out and given to the participant together with a paper describing the procedures to cash the cheque:

With this paper you can withdraw this money from our account at microfinance bank X (name withheld) in Mafinga. Upon presenting this paper, the bank official will pay you the amount written on the paper. The following things are important:

1. It is important that you withdraw this money in the month specified on this paper; otherwise the bank will not be able to pay this money.

2. You are not allowed to write anything on this paper, as this might lead to the bank being unable to pay the money.

3. If you do not withdraw the money personally, but let a relative, friend, etc. do so, it is sufficient that this person shows the paper and mentions your name. 


\section{Web-appendix B: Additional regressions}

Table 2. Determinants of individual discount rates

\begin{tabular}{|c|c|c|c|}
\hline & Model 2bis & Model 3bis & Model 4bis \\
\hline \multirow{2}{*}{ Location $(1=$ rural; $0=$ urban $)$} & $-3.111 * *$ & - & - \\
\hline & $(1.30)$ & - & - \\
\hline \multirow{2}{*}{$\begin{array}{l}\text { Rural and did not visit urban centre in } \\
\text { the last month (dummy) }\end{array}$} & - & $-3.080 * *$ & $-3.362 * *$ \\
\hline & - & $(1.33)$ & $(1.58)$ \\
\hline \multirow{2}{*}{$\begin{array}{l}\text { Rural and did visit urban centre in the } \\
\text { last month (dummy) }\end{array}$} & - & $-3.155^{* *}$ & $-3.384 * *$ \\
\hline & - & $(1.36)$ & $(1.59)$ \\
\hline \multirow{2}{*}{ Age } & 0.006 & 0.006 & 0.006 \\
\hline & $(0.03)$ & $(0.03)$ & $(0.03)$ \\
\hline \multirow{2}{*}{ Education (years) } & $0.275^{* *}$ & $0.277 * *$ & $0.280 * *$ \\
\hline & $(0.12)$ & $(0.12)$ & $(0.12)$ \\
\hline \multirow{2}{*}{ Number of children } & 0.122 & 0.12 & 0.115 \\
\hline & $(0.30)$ & $(0.30)$ & $(0.30)$ \\
\hline \multirow{2}{*}{ Lack of food shortages (dummy) } & $-1.015^{*}$ & $-1.008^{*}$ & $-1.033^{*}$ \\
\hline & $(0.61)$ & $(0.61)$ & $(0.61)$ \\
\hline \multirow{2}{*}{$\operatorname{Sex}(1=$ male $; 0=$ female $)$} & -0.963 & -0.958 & -0.966 \\
\hline & $(0.62)$ & $(0.62)$ & $(0.62)$ \\
\hline \multirow{2}{*}{ Never migrated (dummy) } & 0.607 & 0.608 & 0.601 \\
\hline & $(0.66)$ & $(0.66)$ & $(0.66)$ \\
\hline \multirow{2}{*}{ Household size } & -0.208 & -0.207 & -0.206 \\
\hline & $(0.22)$ & $(0.22)$ & $(0.22)$ \\
\hline \multirow{2}{*}{ Self-employment (crop farming) } & -0.109 & -0.105 & -0.101 \\
\hline & $(1.32)$ & $(1.32)$ & $(1.32)$ \\
\hline \multirow{2}{*}{ Self-employment (livestock raising) } & -0.621 & -0.623 & -0.602 \\
\hline & $(0.74)$ & $(0.74)$ & $(0.74)$ \\
\hline \multirow{2}{*}{ Self-employment (non-farming) } & 0.545 & 0.553 & 0.594 \\
\hline & $(1.41)$ & $(1.41)$ & $(1.42)$ \\
\hline \multirow{2}{*}{ Paid employment } & -0.012 & -0.009 & 0.051 \\
\hline & $(0.73)$ & $(0.74)$ & $(0.74)$ \\
\hline \multirow{2}{*}{ Daily labourer } & -0.182 & -0.191 & -0.267 \\
\hline & $(0.88)$ & $(0.88)$ & $(0.88)$ \\
\hline \multirow{2}{*}{ Access to finance (dummy) } & - & - & -0.351 \\
\hline & - & - & $(1.06)$ \\
\hline \multirow{2}{*}{ Constant } & $16.094 * * *$ & $16.079 * * *$ & $16.385^{* * *}$ \\
\hline & $(2.10)$ & $(2.11)$ & $(2.26)$ \\
\hline Log-likelihood & -3311.99 & -3311.98 & -3300.78 \\
\hline Chi-squared & 130.70 & 130.71 & 130.89 \\
\hline Prob. $>$ chi 2 & 0.0000 & 0.0000 & 0.0000 \\
\hline $\mathrm{N}$ & 1681 & 1681 & 1676 \\
\hline right-censored observations & 459 & 459 & 458 \\
\hline interval observations & 889 & 889 & 886 \\
\hline left-censored observations & 333 & 333 & 332 \\
\hline
\end{tabular}

$* \mathrm{p}<0.10, * * \mathrm{p}<0.05, * * * \mathrm{p}<0.01 ;$ Standard errors between brackets; All models have enumerator fixed effects. 
Table 1. Probit regression on living in urban area

\begin{tabular}{lll}
\hline & Coef. & S.E. \\
\hline Age & $-0.022^{* * * *}$ & 0.004 \\
Education (number of years) & $0.166^{* * * *}$ & 0.017 \\
Number of children & $-0.104 * *$ & 0.042 \\
Lack of food shortages (dummy) & $0.170^{* * *}$ & 0.079 \\
Sex (1 = male; 0 = female) & $-0.708^{* * * *}$ & 0.081 \\
Never migrated (dummy) & $-0.776^{* * *}$ & 0.080 \\
Household size & 0.042 & 0.033 \\
Constant & -0.150 & 0.225 \\
\hline N & 1694 & \\
LR chi2 & 500.13 & \\
Prob. $>$ chi2 & 0.0000 & \\
Pseudo R2 & 0.2697 & \\
\hline
\end{tabular}

Figure 1. Distribution of propensity scores in rural and urban samples

Web-appendix C: Propensity scores

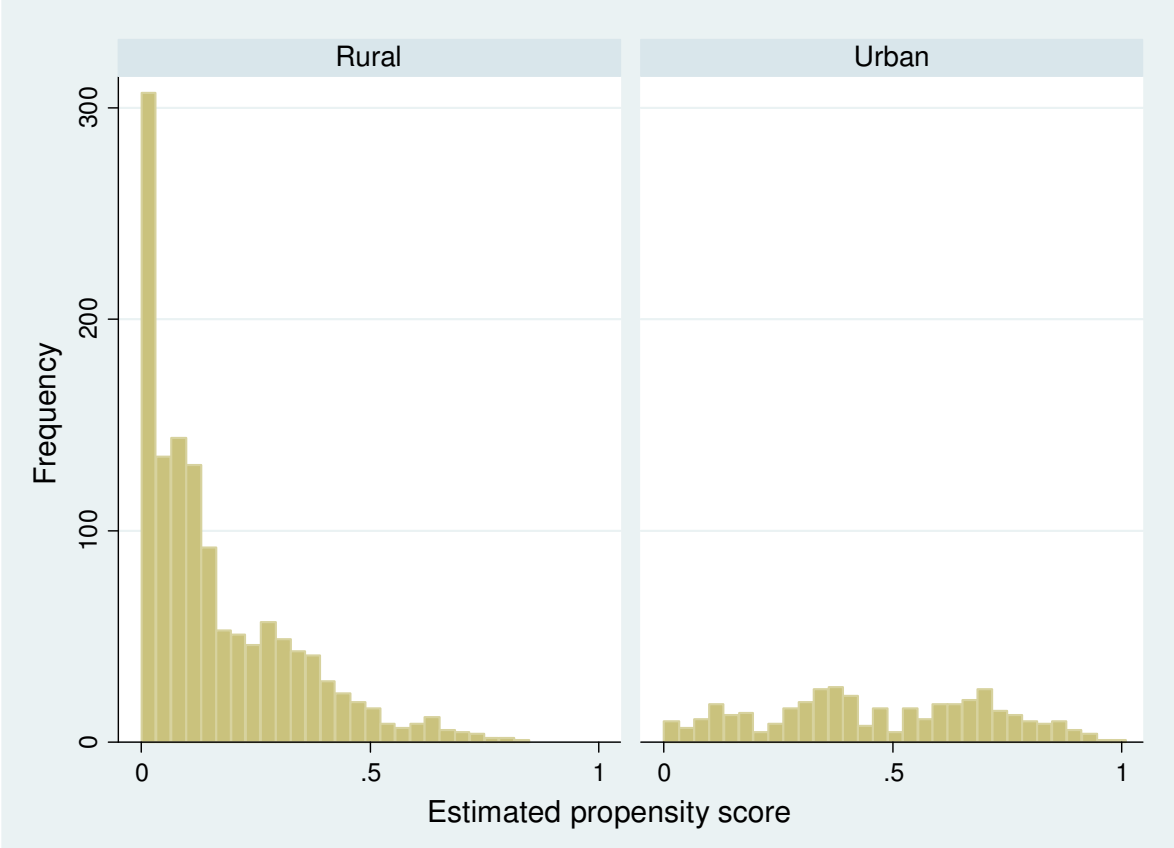

